Check for updates

Cite this: Chem. Sci., 2019, 10, 4015

๑ All publication charges for this article have been paid for by the Royal Society of Chemistry

Received 19th February 2019

Accepted 2nd March 2019

DOI: $10.1039 / \mathrm{c} 9 \mathrm{sc00861f}$

rsc.li/chemical-science

\section{Organogelating and narcissistic self-sorting behaviour of non-preorganized oligoamides $\uparrow$}

\author{
Kun Zheng, Huaizhen Wang (D) and Hak-Fun Chow (D) *
}

Several series of structurally flexible, non-preorganized oligoamides with carboxylic acid, hydride, $N$ propargyl amide and $\mathrm{N}$-propyl amide end groups were synthesized and characterized. They were found to be strong organogelators for aromatic solvents. Both the number and density of the amide units, and the nature of the end group were found to influence the gel strength as well as the kinetics of gel formation. Oligomers with a higher number and density of amide units were found to form stronger gels. Rather unexpectedly, a slight change of the end group could significantly affect the enthalpy and entropy of formation of the resulting self-assembly. Oligomers with the $N$-propargyl amide end group were found to be kinetically trapped in the melted state, which devoid them of forming crystalline zone upon cooling. On the other hand, the corresponding saturated $\mathrm{N}$-propyl amide analog did not show the same effect. Upon mixing of these oligomers, narcissistic self-sorting could be observed in both the wet gel and xerogel states if (i) the difference in the number of amide units is greater than one or (ii) the amide unit densities are different. A semi-quantitative assessment of the extent of self-sorting could be achieved by constructing the corresponding phase diagram of the mixed gel systems. It is concluded that narcissistic self-sorting does not just prevail in mixtures making up of structurally different molecules, but appears to be fairly general even in mixtures of structurally similar molecular homologs.

\section{Introduction}

Molecular self-sorting ${ }^{\mathbf{1 - 4}}$ is a phenomenon which describes the high fidelity recognition between molecules in a complex mixture. If strong affinity for others is exhibited then the selfassembly process is called social self-sorting, while the affinity for itself will be named narcissistic self-sorting. Generally, the driving forces which lead to the self-sorting process are hydrogen bonding, ${ }^{5-7}$ metal-ligand interaction, ${ }^{8-13}$ fluorophobic, ${ }^{14}$ host-guest recognition ${ }^{\mathbf{1 5 , 1 6}}$ and/or dynamic covalent bonding. ${ }^{17-20}$ Controlling the outcome of self-sorting is therefore of pivotal importance in the design and construction of complex functional and responsive soft materials for various applications.

In synthetic systems, careful design and precise control over the placements of the interacting functionalities inside the various components are required before any high fidelity selfsorting process can be realized. In general, high fidelity selfsorting is commonly observed in two scenarios. In the first case, the molecules can be structurally very similar to each other, but they all possess a higher degree of structural rigidity with preorganized interacting units. Self-sorting is manifested

Department of Chemistry, The Chinese University of Hong Kong, Shatin, Hong Kong. E-mail: hfchow@cuhk.edu.hk

$\dagger$ Electronic supplementary information (ESI) available: Synthesis, spectral data, SAXRD, and DSC thermograms. See DOI: 10.1039/c9sc00861f via geometry controlled, such that slight changes in ligand biting angles, metal coordination geometries, complementarity of hydrogen bonding motifs, and shape complementarity in host-guest binding can dedicate the outcome. In the second scenario, self-sorting is non-geometry controlled. The molecular ingredients are either structurally very similar or very different from each other. Rather, the overall molecular properties, such as solubility and miscibility, are much more important in dedicating the outcome. In general, functionally different systems tend to produce narcissistic self-sorting, while social self-sorting is expected from structurally similar systems. The formation of immiscible (phase segregation) or miscible polymer blends actually falls into this category. ${ }^{21}$

Thus far most self-sorting studies have been focused on small, structural rigid and preorganized molecular systems having dissimilar molecular structures. However, there is one uncharted area in self-sorting that remains relatively unexplored. This involves structurally similar and flexible molecules such as oligomeric and polymeric homologs. Although Nature provide the perfect example of social self-sorting involving the pairing of complementary DNA strands, systematic studies of self-sorting phenomenon on synthetic oligomers ${ }^{22,23}$ and polymers $^{24}$ are rare. Normally one would expect that social selfsorting to be the outcome for homologs of oligomers and polymers because of their structural similarity. However, we and others have reported a few counter examples showing that narcissistic self-sorting could actually occur even in structurally 
similar compounds. ${ }^{25-29}$ For examples, Meijer reported that narcissistic self-sorting was found between a mixture of bis(urea)butylene molecule $\mathbf{1}$ and bis(urea)butylene polymer 2 when the amount of 1 was greater than 23 mol\% (Fig. 1). ${ }^{25}$ Kumaki showed that when two narrowly dispersed isotactic poly(methyl methacrylate) (it-PMMA) chains of different lengths were mixed, only chains of the same length formed doublestranded helices, while the formation of heterogeneous double-stranded helices comprising two it-PMMA of different lengths was not observed. ${ }^{26}$ Narcissistic self-sorting can also be manifested in the form of gel formation in multi-component gel system. ${ }^{30}$ In this context, we earlier showed that self-sorting occurred in a mixture of oligoamide gels 3 and $4,{ }^{27}$ and also in polyamide gels 5 and $\mathbf{6 .} .^{28}$ In the case of the oligamides, selfsorting was attributed to the difference in the number of amide units of the two structurally homologous hexamide 3 and dodecaamide 4 . In the case of the polymers 5 and $\mathbf{6}$, the origin of self-sorting was ascribed to the different alignment patterns of the dipole units on the polymer chain.

In the above examples, except for polymers 5 and $\mathbf{6}$, narcissistic self-sorting appeared to be due to the very significant difference in the number of amide units in the two oligomers or polymers. Recent studies ${ }^{31-34}$ by Hunter on hydrogen bonded duplexes formed from the dimerization of two structural flexible oligoamides prompted us to speculate that the observed self-sorting behaviour may be originated from the significant difference of their self-association strengths. In this paper we would like to address several specific questions that are pertaining to our understanding of self-sorting in multicomponent gel systems involving structurally flexible oligoamides. First, how much difference in the number of amide units is needed for two different oligoamides to exhibit self-sorting? Second, is it possible to address the degree of self-sorting semi-quantitatively? If so, does the degree of self-sorting has



Fig. 1 Structural flexible bisurea compound 1 and bisurea polymer 2 , hexaamide 3 and dodecaamide 4, and polyamides 5 and 6 showing narcissistic self-sorting when mixed. Their structural differences are highlighted in red and blue. a strong correlation to the difference in the number of amide motifs? Third, can a difference in the density of the interacting amide units (i.e. number of unit per mass) of two oligomer chains lead to self-sorting? Fourth, can self-sorting be observed in ternary systems involving three different oligoamides? It should be emphasized here that the self-sorting behaviour between structurally similar, non-preorganized molecules are not very well understood. This kind of system is of general interest to our understanding of the underlying mechanisms of self-sorting and will help to extend the scope of applications of multi-component gel systems. This 'mix and match' approach to create multi-component gel systems also represents a highly robust way to create and fine tune the gel properties, and is far more versatile than single component gel systems.

In the present work, we first disclosed the synthesis of three homologous series of oligo(amide-triazole)s 7-9 featuring a $p$ xylylene spacer in the backbone but with three different types of end group, namely, carboxylic acid 7 (OAT-CO $\left.\mathbf{O}_{2} \mathbf{H}-2 n\right)$, hydride $\mathbf{8}$ (OAT-H-2n) and $N$-propargyl amide 9 [OAT-COPrg-(2n+1)], where $2 n$ and $(2 n+1)$ signified the number of $\mathrm{CONH}$ units in the oligomers (Fig. 2). To address the effect of the density of the amide units on the self-sorting behaviour, we also prepared the corresponding elongated analogous series of oligomers 10 (OATe-CO $\left.\mathrm{O}_{2} \mathrm{H}-2 n\right), 11$ (OATe-H-2n) and 12 [OATe-COPrg-(2n+1)] bearing a longer $p$-ethylenylphenyleneethylene spacer. Herein we reported that (i) these oligomers form strong organogels and their gel strength is dependent not only on the number and density of the CONH units, but also on the nature of the end group; (ii) the small end group can exert strong kinetic trapping effects on the enthalpy and entropy of the formation of the resulting self-assembly; (iii) narcissistic self-sorting does exist between these structurally related, non-preorganized homologs in the wet gel and also xerogel states; (iv) the extent of selfsorting can be correlated to the difference in the number and density of the amide units, and is also affected by the nature of the end group and (v) significant difference in the self-sorting behaviour could be found between the samples prepared in the diluted wet gel state $v s$. melted state, and this was mainly controlled by the nature of the end group.

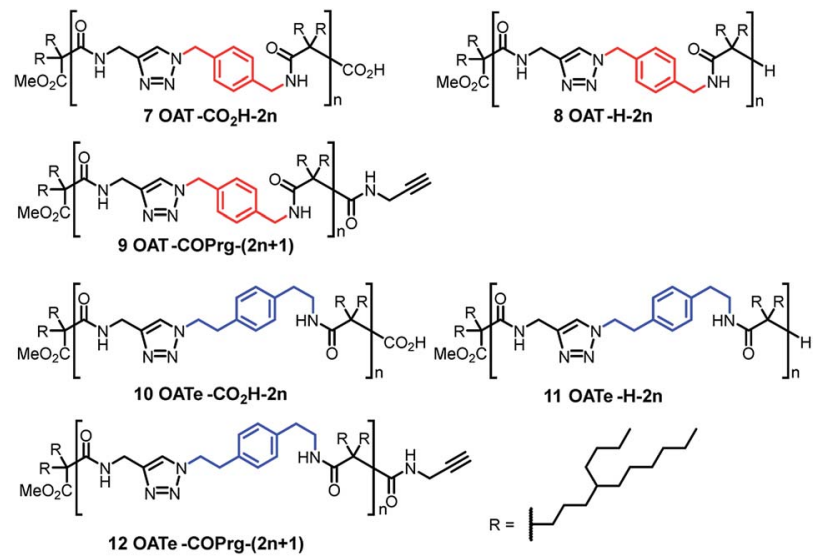

Fig. 2 Structures of oligo(amide-triazole)s synthesized and studied in this research. 


\section{Results and discussion} Synthesis

The oligo-controlled syntheses of OAT- $\mathrm{CO}_{2} \mathbf{H}-2 n$, OAT-COPrg$(2 n+1)$, OATe-CO $\mathrm{O}_{2} \mathrm{H}-2 n$, and OATe-COPrg- $(2 n+1)$ involved an iterative procedure, which was similar to that reported in our previous work. ${ }^{27}$ On the other hand, OAT-H-2n and OATe-H-2n compounds were prepared in situ during annealing $\left(200{ }^{\circ} \mathrm{C}\right.$ for $5 \mathrm{~min}$ ) inside a differential scanning calorimeter. These oligomers all possess a bottlebrush-shaped architecture which minimize the back folding of the backbone. Instead of using a hyperbranched dendron as previously disclosed, a racemic 4butyldecyl (i.e. R) group was used as the side chain. This strategy avoided the tedious preparation of the dendron and also led to an enhancement of the solubility of the target compounds. Furthermore, in addition to the $(n+1)$ iterative approach, a $(n+2)$ approach was also adopted to grow the higher oligomers. The latter approach allowed the addition of four additional $\mathrm{CONH}$ units in one iterative cycle and improved the synthetic efficiency significantly.

To begin with, several key intermediates 13-17 were firstly prepared from commercially available materials (Fig. 3). ${ }^{35}$ Compound $\mathbf{1 3}$ is an acetylenic partner that was used to couple with various propagating azido units 14-17 to furnish the target oligomers. Hence, diamide OAT-CO $\mathbf{O}_{2} \mathbf{H}-2$ was prepared via CuAAC click coupling $\left(\mathrm{CuSO}_{4} \text { and sodium ascorbate }\right)^{36}$ between compounds 13 and 14 in 86\% yield (Scheme 1). Employing the $(n+1)$ iterative synthetic cycle, amidation of OAT-CO $\mathbf{O}_{2} \mathbf{H}-2$ then gave the triamide OAT-COPrg-3 in 65\% yield in the presence of 1-[3-(dimethylamino)propyl]-3-ethylcarbodiimide methiodide (EDCI) and 1-hydroxybenzotriazole (HOBt). Further click coupling of OAT-COPrg-3 and the propagating unit 14 then produced the tetramide OAT- $\mathbf{C O}_{2} \mathbf{H}-4$ in $79 \%$ yield. Repetition of the same reaction cycle then afforded OAT-COPrg-5, OAT- $\mathrm{CO}_{2} \mathbf{H}$ 6 and OAT-COPrg-7 in 78, 89 and 80\% yield, respectively. Significantly difference in the chromatographic mobilities of the OAT-CO $\mathbf{O}_{2} \mathbf{H}-2 n$ and OAT-COPrg-(2n+1) ensured that no crosscontamination product was carried down in the subsequent synthesis, thus exerting full oligo-controlled synthesis of the target oligomers.

For the synthesis of the longer oligomers, the $(n+2)$ approach was adopted by using the longer propagating unit 15 (Scheme 2). For example, click reaction between OAT-COPrg-5 and 15 gave OAT-CO $\mathbf{C}_{2} \mathbf{H}-8$ in $96 \%$ yield. Subsequent amidation with propargylamine in the presence of $N, N$-diisopropylethylamine (DIPEA)

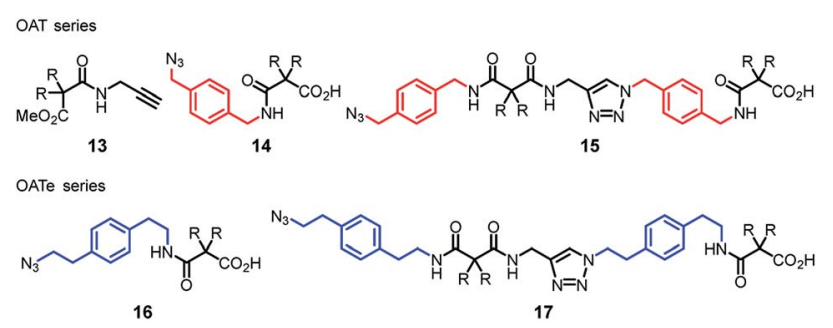

Fig. 3 Key compounds 13-17 required for the synthesis of oligo(amide-triazole)s OAT and OATe.

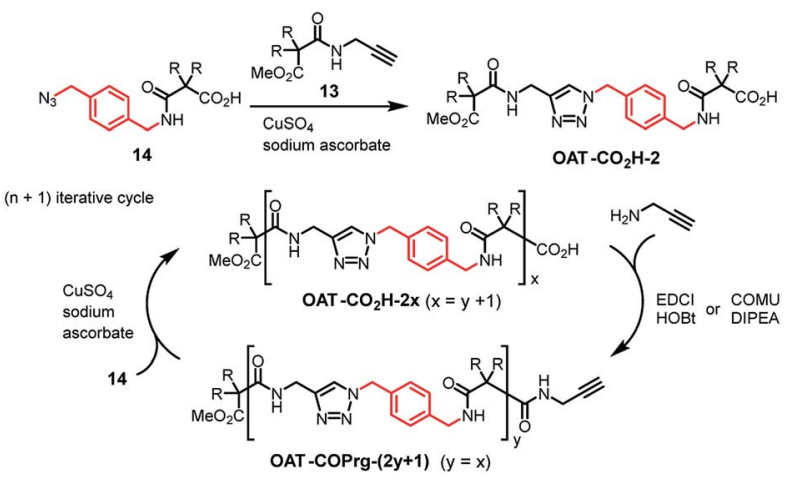

Scheme 1 Synthesis of oligomers OAT- $\mathrm{CO}_{2} \mathrm{H}-2 x$ and OAT-COPrg$(2 y+1)$ using an $(n+1)$ iterative approach.

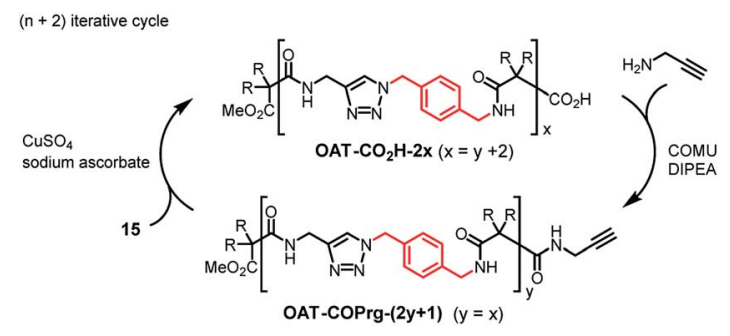

Scheme 2 Synthesis of oligomers OAT- $\mathrm{CO}_{2} \mathrm{H}-2 x$ and OAT-COPrg$(2 y+1)$ using an $(n+2)$ iterative approach.

and 1-cyano-2-ethoxy-2-oxoethylidenaminooxy-dimethylaminomorpholinocarbenium hexafluorophosphate (COMU) then afforded OAT-COPrg-9 in 79\% yield. In a similar manner, OAT- $\mathbf{C O}_{2} \mathbf{H}$ 10, OAT-COPrg-11 and OAT- $\mathrm{CO}_{2} \mathrm{H}-12$ could be obtained. In the synthesis cycles, the yields of click reaction were around 66-96\% and for the coupling reactions were $65-80 \%$.
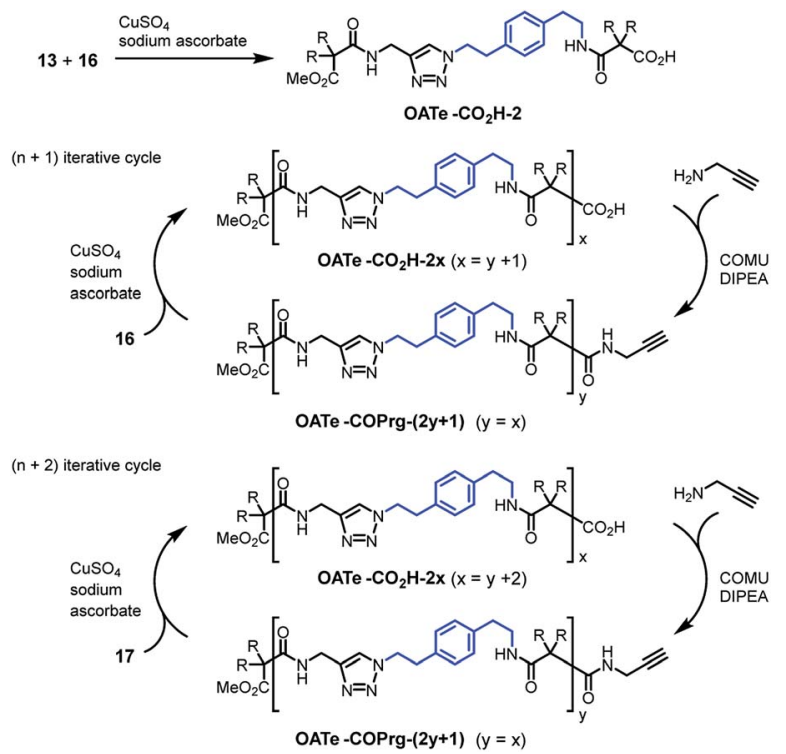

Scheme 3 Synthesis of oligomers OATe- $\mathrm{CO}_{2} \mathrm{H}-2 x$ and OATe-COPrg$(2 y+1)$ using the $(n+1)$ and $(n+2)$ approaches. 
For the OATe series, propagating units 16 and 17 were used for the $(n+1)$ and $(n+2)$ iterative cycles, respectively (Scheme 3$)$. The elongated diamide $\mathbf{O A T e}-\mathrm{CO}_{2} \mathbf{H}-2$ was prepared by click coupling between compounds 13 and 16 in $82 \%$ yield. Using the $(n+1)$ route, OATe-COPrg-3, OATe- $\mathrm{CO}_{2} \mathrm{H}-4$, OATe-COPrg-5, OATe- $\mathrm{CO}_{2} \mathbf{H}-6$ and OATe-COPrg-7 were synthesized, while OATe$\mathrm{CO}_{2} \mathbf{H}-8$, OATe-COPrg-9 and OATe- $\mathrm{CO}_{2} \mathrm{H}-10$ were prepared via the $(n+2)$ approach by using compound $\mathbf{1 7}$ as the propagating unit. In the synthesis cycles, the yields of click reactions were $77-88 \%$ and for amide formation reactions were $66-92 \%$.

\section{Structural characterizations}

The structural identities of all prepared compounds were characterized by ${ }^{1} \mathrm{H}$ and ${ }^{13} \mathrm{C}$ NMR spectroscopy, and the results were consistent with the proposed structure. ${ }^{35}$ The degree of oligomerization could be confirmed by mass spectrometry and ${ }^{1} \mathrm{H}$ NMR end group analysis. ${ }^{35}$ Hence, all the target oligomers were prepared in high purity with no cross-contamination.

\section{Organogelation properties}

Gelation strength. Traditionally, the minimum gelation concentration (MGC) and gel-to-sol transition temperature $\left(T_{\mathrm{gs}}\right)$ are the two commonly used parameters to assess the gel strength of a series of structurally related organogelators. However, these two methods possess some inherent limitations which could lead to misleading conclusions. First, MGC data are rather crude and may not be able to differentiate gel strength of similar magnitude. Second, at the $T_{\text {gs }}$ point, the gel and sol states are in equilibrium, so the Gibbs free energy change is zero (i.e. $\Delta G_{\mathrm{gs}}=\Delta H_{\mathrm{gs}}-T_{\mathrm{gs}} \Delta S_{\mathrm{gs}}=0$, or $T_{\mathrm{m}}=\Delta H_{\mathrm{gs}}$ l $\left.\Delta S_{\mathrm{gs}}\right)$. Hence, using the $T_{\mathrm{gs}}$ values to compare the relative stability (i.e. $\Delta H_{\mathrm{gs}}$ ) of two gels is only valid when the entropy of changes $\left(\Delta S_{\mathrm{gs}}\right)$ of the two systems are equal. While the latter proposition is likely to be valid for compounds of similar structure and molecular weight, this is certainly not the case among oligomers of different lengths as $\Delta S_{\mathrm{gs}}$ should be size dependent. As a result, the gel-to-sol enthalpy changes $\left(\Delta H_{\mathrm{gs}}\right)$ will be used to assess the wet gel strength. Incidentally, the $\Delta S_{\mathrm{gs}}$ data could also provide additional information regarding the structural orderliness of the gel assembly.

For the OAT series, stable organogels in aromatic solvents could be formed when the minimum number of CONH units was 6, while this number was 7 for the OATe series. The enthalpy and entropy data (shown in a per gram basis) obtained from differential scanning calorimetry (DSC) studies provided more revealing insights (Table 1). For these oligomers, the number of amide units is directly proportional to its molecular weight, therefore the presented data roughly reflected the relevant values on a per amide unit basis. First, within the same series and with the same end group, the $\Delta H_{\mathrm{gs}}$ value increased monotonically as the oligomer length became longer, indicating that each CONH unit in the longer oligomer contributes stronger to the stability of the gel network than that in a shorter oligomer. This synergistic multiple functional group binding effect had been demonstrated earlier by Hunter $^{37}$ and also by us. ${ }^{27,38}$ However, the increment began to

Table 1 Enthalpy $\left(\Delta H_{\mathrm{gs}}\right)$ and entropy $\left(\Delta \mathrm{S}_{\mathrm{gs}}\right)$ changes of gel-to-sol transition of $p$-xylene gels (conc. $=25 \mathrm{mg} \mathrm{mL}^{-1}$ ) of OAT and OATe oligomers $^{a}$

\begin{tabular}{llllll}
\hline Compound & $\begin{array}{l}\Delta H_{\mathrm{gs}} \\
\left(\mathrm{J} \mathrm{g}^{-1}\right)\end{array}$ & $\begin{array}{l}\Delta S_{\mathrm{gs}} \times 10^{3} \\
\left(\mathrm{~J} \mathrm{~g}^{-1} \mathrm{~K}^{-1}\right)\end{array}$ & Compound & $\begin{array}{l}\Delta H_{\mathrm{gs}} \\
\left(\mathrm{J} \mathrm{g}^{-1}\right)\end{array}$ & $\begin{array}{l}\Delta S_{\mathrm{gs}} \times 10^{3} \\
\left(\mathrm{~J} \mathrm{~g}^{-1} \mathrm{~K}^{-1}\right)\end{array}$ \\
\hline
\end{tabular}

Acids

OAT- $\mathrm{CO}_{2} \mathrm{H}-6 \quad 12.0 \quad 38.7$

OAT- $\mathrm{CO}_{2} \mathrm{H}-8 \quad 23.2 \quad 67.5$

OAT- $^{-O_{2}} \mathbf{H}-10 \quad 24.9 \quad 69.3$

OAT- $-\mathrm{CO}_{2} \mathrm{H}-12 \quad 28.5 \quad 78.2$

Amides

OAT-COPrg-7 $\quad 26.8 \quad 83$

OAT-COPrg-9 $\quad 39.5 \quad 114$

OAT-COPrg-11 $39.9 \quad 112$

${ }^{a}$ Gels were aged in the sealed crucible at $25{ }^{\circ} \mathrm{C}$ for 20 min prior to measurements. Heating profile: $25{ }^{\circ} \mathrm{C}$ to $100{ }^{\circ} \mathrm{C}$ at a rate of $5{ }^{\circ} \mathrm{C} \mathrm{min}^{-1}$. $p$-Xylene was used as the reference in the measurements.

level off when the CONH units became very large (OAT-COPrg9 vs. OAT-COPrg-11), implying the presence of a plateauing effect. Second, the strength of the OAT gels was always greater than that of corresponding OATe gels having the same number of CONH (OAT-COPrg-7 vs. OATe-COPrg-7, OAT- $\mathrm{CO}_{2} \mathrm{H}-10$ vs. OATe- $\mathbf{C O}_{2} \mathbf{H}-10$ ), which proved that a decrease in the density of CONH unit could weaken the gel network. Third, the end group played a very important role in determining the gel strength. The gels formed from oligomers bearing the $\mathrm{N}$ propagaryl amide end group were more stable than the ones with one less amide unit but bearing the $\mathrm{CO}_{2} \mathrm{H}$ end group (OAT-COPrg-7 > OAT-CO $\mathrm{O}_{2} \mathrm{H}-8$, OAT-COPrg-9 > OAT-CO $\mathrm{O}_{2} \mathrm{H}-10$ ). Fourth, from the $\Delta S_{\mathrm{gs}}$ data, it was found that the longer oligomers always possessed a higher degree of structural order in the self-assembled gel state than the shorter oligomers for both the OAT and OATe series. Incidentally, it was also noted that the OAT oligomers formed a more order supramolecular assembly than the corresponding OATe oligomers, and that the $\mathrm{N}$ propargyl amide end group also conferred higher packing order than the carboxylic acid end group. As the entropic contribution to the gelation was very different even for compounds of very similar structure, this confirmed that the simple use of $T_{\mathrm{gs}}$ or MGC values to compare gel strength is not reliable.

Gelation mechanism. Having established the number and density of the CONH units and the end group effects on the gel strength, the gelation mechanism was then examined first by Fourier-transformed infrared (FTIR) spectroscopy. A comparison of the FTIR spectra of the non-gelator OAT-CO $\mathbf{C}_{2} \mathbf{H}-4$ (2.5\% $\mathrm{w} / \mathrm{v}$ solution in $p$-xylene) showed the adsorptions at around 3430 and $3350 \mathrm{~cm}^{-1}$ due to the non-hydrogen-bonded amide $\mathrm{N}-\mathrm{H}$ stretching frequencies (Fig. 4). They were found to shift to $3370 \mathrm{~cm}^{-1}$ and $3280 \mathrm{~cm}^{-1}$ in the spectra of the gelators OAT$\mathrm{CO}_{2} \mathbf{H}-8$ and OAT-COPrg-9 (2.5\% w/v gel in $p$-xylene). Similarly, the stretching frequencies of the primary amide $\mathrm{C}=\mathrm{O}$ also shifted from $1680 \mathrm{~cm}^{-1}$ to $1650 \mathrm{~cm}^{-1}$. The FTIR results strongly proved that the amide groups were involved in the hydrogen- 


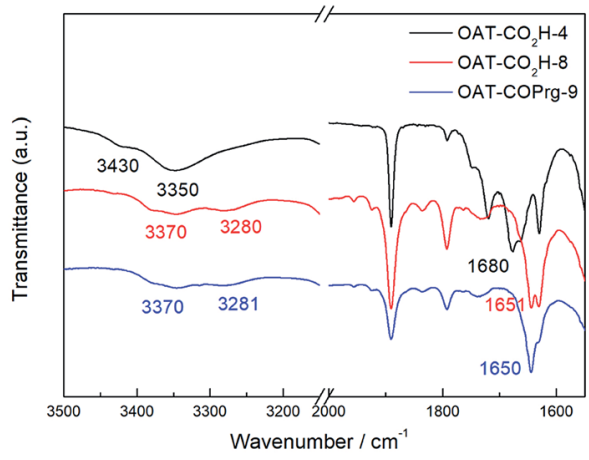

Fig. 4 Stacked FTIR spectra of OAT- $\mathrm{CO}_{2} \mathrm{H}-4$ (2.5\% solution in $p$ xylene), OAT- $\mathrm{CO}_{2} \mathrm{H}-8$ (2.5\% gel in $p$-xylene) and OAT-COPrg- $9(2.5 \%$ gel in $p$-xylene).

bonding process which was responsible for the gelation property of these oligomers.

Gelation model. To explore the gel packing arrangement of the crystallization zone in the molecular scale, OAT-COPrg-5, OAT- $\mathrm{CO}_{2} \mathrm{H}-6$, OAT-COPrg-9 and OAT- $\mathrm{CO}_{2} \mathrm{H}-12$ were subjected to small angle X-ray diffraction (SAXRD) analysis. For OAT-COPrg5 which could not form gel in $p$-xylene, no obvious peaks were found (Fig. 5). For the three remaining gelating oligomers, they all showed a similar pattern with two peaks at $2 \theta=5.8^{\circ}$ and $18.8^{\circ}$. The sharper peak at $5.8^{\circ}$ was originated from a $d$-spacing of $15.0 \AA$, which was shorter than twice the span of the 4butyldecyl side chain $(2 \times 13.5 \AA)$. Another broad peak at $18.8^{\circ}$ with a $d$-spacing of $4.7 \AA$ fell into the range of the interatomic distance of $\pi-\pi$ stacking. These peaks were not well resolved, indicating that the ordering of individual molecules inside the xerogel was low. This is most likely due to the backbone flexibility of the long oligomer chain and also each of the oligomers is actually a heterogeneous mixture of diastereomers, which prevent their orderly packing. Nonetheless, the result suggested that gel formation was due to the interdigitation of the hydrophobic side chains and $\pi-\pi$ stacking interactions of the backbone aromatic moieties. The packing structures of OAT- $\mathbf{C O}_{2} \mathbf{H}-$ $2 n$ and OAT-COPrg-(2n+1) were very similar which indicated that neither the nature of the end group nor the oligomer length would lead to obviously different nanostructures. Similar

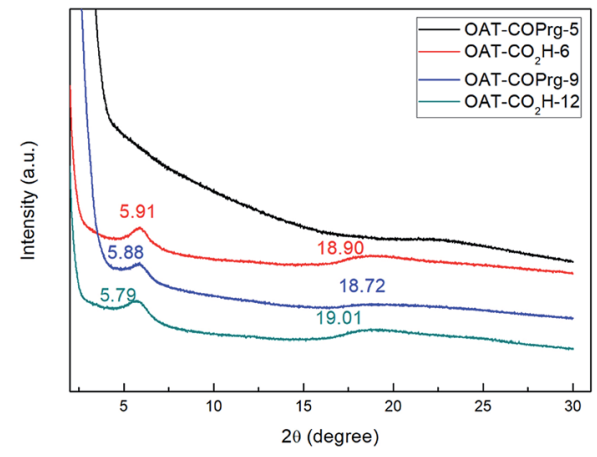

Fig. 5 SAXRD patterns of $2.5 \%$ freeze dry $p$-xylene solution sample of OAT-COPrg-5, and $2.5 \%$ xerogel samples from $p$-xylene of OAT$\mathrm{CO}_{2} \mathrm{H}-6$, OAT-COPrg- 9 and OAT- $\mathrm{CO}_{2} \mathrm{H}-12$. results were also obtained in the patterns of the elongated series OATe-COPrg-7 and OATe- $\mathrm{CO}_{2} \mathbf{H}-10$ (ESI Fig. S3, pS34†).

To further investigate the self-assembly model of OAT and OATe compounds at the nanoscale, we would like to learn whether our oligoamides could also form duplexes similar to those reported by Hunter. ${ }^{31-34}$ Hence, ${ }^{1} \mathrm{H}$ NMR dilution experiment was carried out using $\mathbf{O A T}-\mathrm{CO}_{2} \mathbf{H}-6$ in $\mathrm{CDCl}_{3}$ in order to determine the binding constant. As it turned out, the data fitted very well $\left(r^{2}=0.999\right)$ to a dimerization model with a $K_{\mathrm{dim}}=2$ $\mathrm{M}^{-1}$ (ESI Fig. S5 and Table S1, p S35†), indicating the binding was very weak. Besides OAT- $\mathbf{C O}_{2} \mathbf{H}-6$, we also carried out the NMR dilution experiments on OAT-COPrg-7, OAT-COPrg-9 and OAT- $\mathrm{CO}_{2} \mathrm{H}-10$ in $\mathrm{CDCl}_{3}$, but the results did not fit the dimerization model. It was rationalized that our oligomers did not simply bind in a dimeric fashion, as a gel network could only be formed via the supramolecular crosslinking involving many oligomer molecules.

Xerogels of OAT- $\mathrm{CO}_{2} \mathrm{H}-12$ and OATe- $\mathrm{CO}_{2} \mathrm{H}-10$ were prepared and subjected to scanning electron microscopy (SEM) examinations to reveal the morphology of the network structure (Fig. 6). All the images presented lamellar assemblies which were further linked by entangled fibers or bundles. A gel model was proposed based on the SAXRD and SEM results (Fig. 7). First, the individual oligomers self-associated via intermolecular hydrogen bonding and $\pi-\pi$ stacking interactions to form bundles. The bundles then further interacted via side chain interdigitation to form lamellar structures that were capable of trapping solvent molecules. It should be noted that the oligomer chains are not bundled up in a regular fashion (i.e. some oligomer chain ends protrude out from the pack while some ends bury inside the interior).

\section{End group effect on the kinetics and stability of the self- assembled organogels}

While most research works on gels focus on their gelation strength and their associated applications, the kinetics of gel formation is less explored. In our earlier DSC studies, it had already been shown that the end group made significant influence on the packing arrangement and also the strength of the gel network. In order to gain more information of the gel assembly, the xerogel samples prepared by freeze drying of wet $p$-xylene gels (hereafter named as initial samples), were firstly heated at a rate of $10{ }^{\circ} \mathrm{C} \mathrm{min}{ }^{-1}$ from $40{ }^{\circ} \mathrm{C}$ to $200{ }^{\circ} \mathrm{C}$ to obtain the first heating
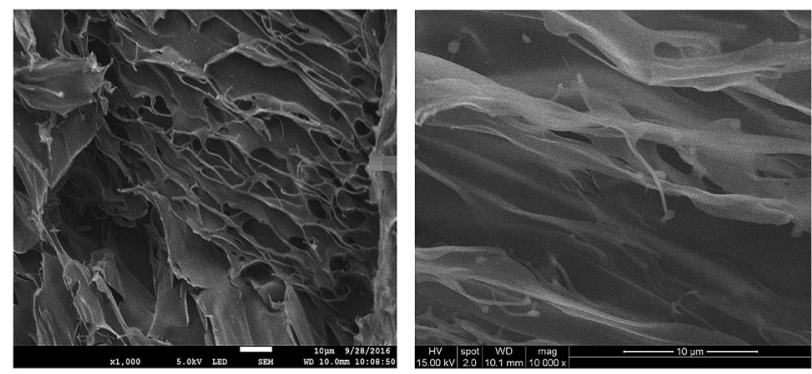

Fig. 6 SEM images (20k magnification) of freeze-dried 1.5\% gels in $p-$ xylene (left) OAT- $\mathrm{CO}_{2} \mathrm{H}-12$ and (right) OATe- $\mathrm{CO}_{2} \mathrm{H}-10$. 
(a)

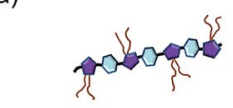

(b)
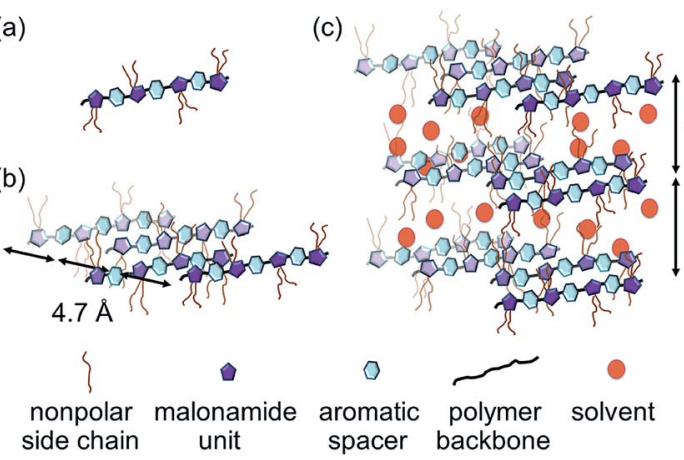

Fig. 7 Self-assembling model of oligomer gel. (a) Free oligomer chain (b) Oligomer bundle formation via $\pi-\pi$ stacking interaction. (c) Gel network formation via side chain interdigitation and solvent entrapment.

profile. The samples were then subjected to annealing at $200{ }^{\circ} \mathrm{C}$ for $5 \mathrm{~min}$, then cooling down at a rate of $5^{\circ} \mathrm{C} \mathrm{min}{ }^{-1}$ back to $40^{\circ} \mathrm{C}$, and the annealed samples were reheated to obtain the second heating curve. Rather unexpectedly, it was found that end group, the method of xerogel preparation (initial sample $v s$. annealed sample) and the cooling rate all had significant impact on the thermodynamic stability of the xerogels.

$\boldsymbol{N}$-Propargyl amide end group. The solid-to-liquid transition temperature $\left(T_{\mathrm{m}}\right)$ of the xerogel did not change much for the first and second heatings for all the OAT-COPrg-(2n+1) samples. However, both the enthalpy $\left(\Delta H_{\mathrm{m} 2}=5.0 \mathrm{~J} \mathrm{~g}^{-1}\right)$ and entropy of melting $\left(\Delta S_{\mathrm{m} 2}=11.3 \times 10^{-3} \mathrm{~J} \mathrm{~g}^{-1} \mathrm{~K}^{-1}\right)$ values of the annealed samples decreased sharply as compared to those $\left(\Delta H_{\mathrm{m} 1}=34.2 \mathrm{~J}\right.$ $\mathrm{g}^{-1}$ and $\Delta S_{\mathrm{m} 1}=87.9 \times 10^{-3} \mathrm{~J} \mathrm{~g}^{-1} \mathrm{~K}^{-1}$ ) of the initial samples (Fig. 8 and ESI Fig. S8-S9, pS37†). This was not due to sample decomposition as the ${ }^{1} \mathrm{H}$ NMR spectra of the initial and annealed samples were the same (ESI Fig. S18, pS45 $\dagger$ ). When the annealed OAT-COPrg-7 sample was subjected to wet gel formation followed by freeze drying, the DSC profile of the initial sample re-emerged, which indicated that such a change of the DSC profile was due to a difference of the self-assembly structures prepared from freeze drying of a wet gel $v s$. from cooling of a melted gel. The diminishment of $\Delta H_{\mathrm{m}}$ and $\Delta S_{\mathrm{m}}$ values implied a weakening of the stability of the self-assembling structure and also a reduction of ordered crystalline zones of the annealed samples. This suggested that in the melted state, the oligomers were entangled and were unable to pack into the most stable self-assembly structure due to kinetic entrapment. More interestingly, lowering the cooling rate from $5{ }^{\circ} \mathrm{C} \mathrm{min}^{-1}$ to $1^{\circ} \mathrm{C} \mathrm{min}^{-1}$, the drop of $\Delta H_{\mathrm{m} 2}(5.0$ $\rightarrow 10.4 \mathrm{~J} \mathrm{~g}^{-1}$ ) became less, while increasing the cooling rate from $5{ }^{\circ} \mathrm{C} \mathrm{min}{ }^{-1}$ to $10{ }^{\circ} \mathrm{C} \mathrm{min}^{-1}$ led to further dropping of $\Delta H_{\mathrm{m} 2}(5.0$ $\rightarrow 2.9 \mathrm{~J} \mathrm{~g}^{-1}$ ) (ESI Table S3, pS38†). The results proved that the diminution of the endothermic peak in the second cycle was because that the self-assembly ability of OAT-COPrg-(2n+1) in melted state was worse than that in the diluted solution state. In the case of the length extended OATe-COPrg-(2n+1) series, no $T_{\mathrm{m}}$ could be identified in the annealed samples, although a solid-toliquid transition could be found in the initial samples (ESI Fig. S9, pS37†). This finding implied that chain entanglement in the melted state was very severe in the elongated OATe oligomers such that no-crystalline zone could be formed during cooling of the melted state.

$\boldsymbol{N}$-Propyl amide end group. To further understand the end group effect on the self-assembling process, the saturated analog of OAT-COPrg-7 (i.e. $N$-propyl amide, OAT-COProp-7) was prepared..$^{35}$ To our surprise, the $\Delta H_{\mathrm{m}}$ and $\Delta S_{\mathrm{m}}$ values of OATCOProp-7 before and after annealing were very similar (Fig. 8), which proved that the terminal $\mathrm{C} \equiv \mathrm{C}$ unit of OAT-COPrg-7 was responsible for its inferior self-assembly ability in the melted state. This finding revealed that even a tiny structural difference could change the kinetic as well as the thermodynamic aspects of the molecular self-assembly process. In fact, Bouteiller had similarly shown that changing an alkyl to alkenyl substituent in bisurea derivatives could strongly affect the self-assembly structure, and had suggested that either steric repulsion between the alkenyl and alkyl groups or favourable solvation of the alkenyl group could be the reasons for the observed phenomenon. ${ }^{39}$

Carboxylic acid end group. Comparing the DSC profiles of the initial and annealed samples bearing the carboxylic acid end group (OAT-CO $\mathbf{O}_{2} \mathbf{H}-6$ and $\left.\mathbf{O A T}-\mathbf{C O}_{2} \mathbf{H}-8\right)$, it was found that the $T_{\mathrm{m}}$ were different for the initial and annealed samples, while the $\Delta H_{\mathrm{m}}$ values remained essentially the same (Fig. 9 and Table 2). In order to figure out what happened during annealing, the annealed sample was subjected to ${ }^{1} \mathrm{H}$ NMR analysis (ESI Fig. S17, pS45 $\dagger$ ). The ${ }^{1} \mathrm{H}$ NMR solution spectra $\left(\mathrm{CDCl}_{3}\right)$ of all the annealed OAT- $\mathrm{CO}_{2} \mathbf{H}-2 n$ showed that one of the amide NHs was upfield shifted to $\sim 5.8 \mathrm{ppm}$ as compared to that of the corresponding initial samples, which indicated that this $\mathrm{NH}$ was positioned in a weaker hydrogen-bonding environment after

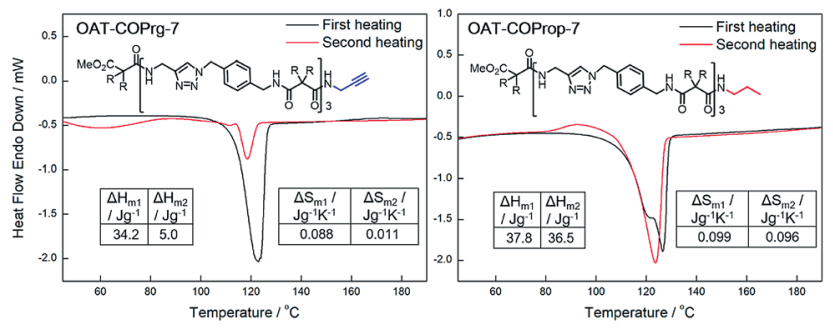

Fig. 8 DSC thermograms for xerogels of OAT-COPrg-7 and OATCOProp-7 prepared from $p$-xylene (conc. $=2.5 \%$ ). Black: initial samples, red: annealed samples.
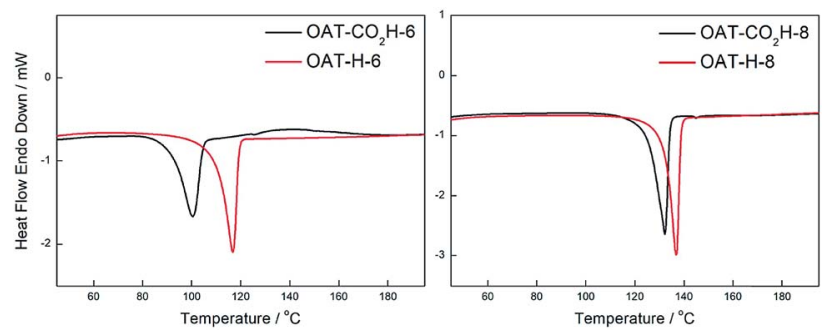

Fig. 9 DSC thermograms for xerogels of initial and annealed decarboxylated samples of OAT- $\mathrm{CO}_{2} \mathrm{H}-6$ and OAT- $\mathrm{CO}_{2} \mathrm{H}-8$ prepared from $p$-xylene (conc. $=2.5 \%$ ). Black: initial samples, red: annealed decarboxylated samples. 
Table 2 Melting temperature $\left(T_{m}\right)$ and enthalpy change of melting $\left(\Delta H_{\mathrm{m}}\right)$ of xerogels of initial ${ }^{a}$ and annealed decarboxylated ${ }^{b}$ samples of OAT- $-\mathrm{CO}_{2} \mathrm{H}-2 n$

\begin{tabular}{|c|c|c|c|c|c|}
\hline $\begin{array}{l}\text { First heating } \\
\text { initial } \\
\text { sample }\end{array}$ & $\begin{array}{l}T_{\mathrm{m}} \\
\left({ }^{\circ} \mathrm{C}\right)\end{array}$ & $\begin{array}{l}\Delta H_{\mathrm{m}} \\
\left(\mathrm{J} \mathrm{g}^{-1}\right)\end{array}$ & $\begin{array}{l}\text { Second heating } \\
\text { decarboxylated } \\
\text { sample }\end{array}$ & $\begin{array}{l}T_{\mathrm{m}} \\
\left({ }^{\circ} \mathrm{C}\right)\end{array}$ & $\begin{array}{l}\Delta H_{\mathrm{m}} \\
\left(\mathrm{J} \mathrm{g}^{-1}\right)\end{array}$ \\
\hline OAT-CO ${ }_{2} \mathrm{H}-6$ & 100 & 21.0 & OAT-H-6 & 117 & 20.3 \\
\hline OAT-CO ${ }_{2} \mathrm{H}-8$ & 132 & 25.0 & ОАТ-H-8 & 137 & 24.8 \\
\hline OAT-CO $\mathrm{O}_{2} \mathrm{H}-10$ & 149 & 29.9 & OAT-H-10 & 149 & 27.2 \\
\hline OAT-CO ${ }_{2} \mathrm{H}-12$ & 155 & 30.7 & ОАТ-H-12 & 154 & 24.8 \\
\hline
\end{tabular}

${ }^{a}$ Xerogels were prepared from freeze drying of a $p$-xylene gel sample of gelator conc. $=25 \mathrm{mg} \mathrm{mL}{ }^{-1} \cdot{ }^{b}$ Annealing was conducted at $200{ }^{\circ} \mathrm{C}$ for 5 min.

annealed once. Additionally, a new small peak showed up at 2.1 ppm. Based on this evidence, it was concluded that a decarboxylation had taken place during the annealing process, which resulted in the disappearance of intramolecular hydrogen-bonding interaction between the $\mathrm{NH}$ and carbonyl moiety of carboxylic acid end group. The new peak at $2.1 \mathrm{ppm}$ should therefore be the signal of the newly generated $\mathrm{CH}$. The chemical identity of the decarboxylated samples was further confirmed by mass spectral analysis (ESI Section 10†). Hence, all annealed OAT- $\mathrm{CO}_{2} \mathbf{H}-2 n$ compounds were actually the corresponding OAT-H-2n derivatives.

The fact that a decarboxylation reaction took place during annealing of the OAT- $\mathbf{C O}_{2} \mathbf{H}-2 n$ derivatives prompted us to reinvestigate the minimum temperature required for such a transformation. It was later determined that partial decarboxylation reaction happened only when a solution of OAT$\mathrm{CO}_{2} \mathbf{H}-2 \mathrm{n}$ was heated to about $138{ }^{\circ} \mathrm{C}$. Hence, all wet gel samples of OAT- $\mathrm{CO}_{2} \mathrm{H}-2 n$ were prepared at below $120{ }^{\circ} \mathrm{C}$ in order to preserve their structural integrity.

\section{Molecular self-sorting}

The self-sorting studies were performed by DSC examinations since it is a simple and straight-forward method to reveal the thermodynamic properties of the pure and mixed samples. For two miscible compounds, only one broad endothermic peak will appear upon heating and the melting temperature will locate between those of the two pure samples. However, for a self-sorted binary system, two endothermic peaks will be observed.

Self-sorting between OATs with different change length. We first conducted self-sorting of organogels involving twocomponent binary system of oligomers of different change length (i.e. different number of CONH units). The DSC thermogram of a 1 : 1 mixed xerogel of OAT-CO $\mathbf{O}_{2} \mathbf{H}-6(1.25 \% \mathrm{w} / \mathrm{v})$ and OAT- $\mathrm{CO}_{2} \mathbf{H}-8(1.25 \% \mathrm{w} / \mathrm{v})$ was compared to that of pure xerogel of OAT-CO $\mathbf{C O}_{2} \mathbf{H}-6(2.5 \% \mathrm{w} / \mathrm{v})$ and pure xerogel of $\mathbf{O A T}-\mathrm{CO}_{2} \mathbf{H}-8$ $(2.5 \% \mathrm{w} / \mathrm{v})$ (Fig. 10a). Two slightly overlapping peaks $\left(102{ }^{\circ} \mathrm{C}\right.$ and $119^{\circ} \mathrm{C}$ ) were identified in the mixed sample and each of them was in a similar position to that of the pure sample respectively. This indicated that some degree of self-sorting could be observed even when the difference of $\mathrm{CONH}$ units between the two OAT- $\mathbf{C O}_{2} \mathbf{H}-2 n$ was just two. The slightly decrease of the two
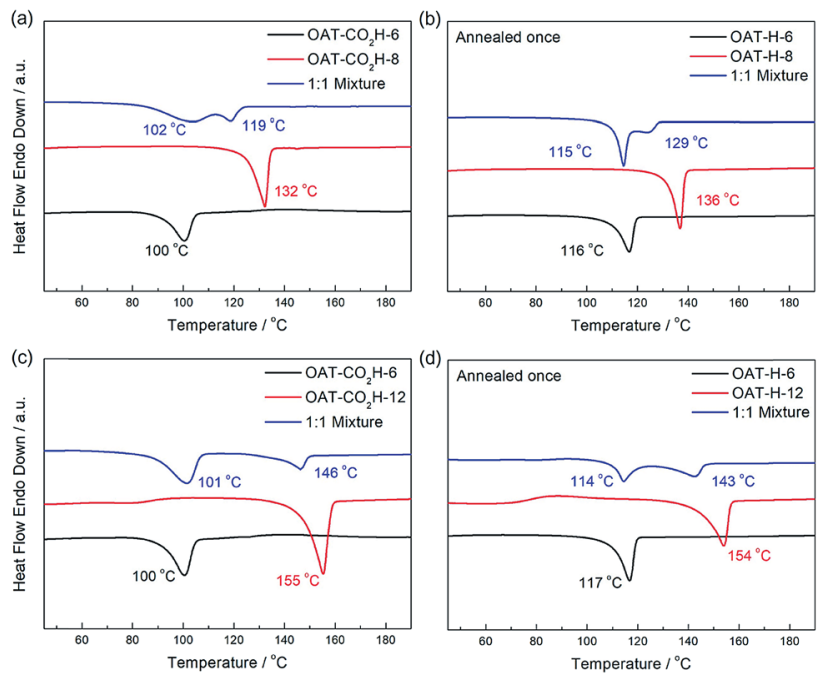

Fig. 10 (a) DSC thermograms of xerogels (2.5\% w/v in $p$-xylene) of a $1: 1$ mixture of OAT- $\mathrm{CO}_{2} \mathrm{H}-6 / \mathrm{OAT}-\mathrm{CO}_{2} \mathrm{H}-8$ (blue), pure OAT$\mathrm{CO}_{2} \mathrm{H}-8$ (red), and pure OAT- $\mathrm{CO}_{2} \mathrm{H}-6$ (black); (b) DSC thermograms of xerogels of a 1 : 1 mixture of OAT-H-6/OAT-H-8 (blue), pure OAT-H- 8 (red), and pure OAT-H-6 (black); (c) DSC thermograms of xerogels $\left(2.5 \% \mathrm{w} / \mathrm{v}\right.$ in $p$-xylene) of a $1: 1$ mixture of OAT- $\mathrm{CO}_{2} \mathrm{H}-6 / \mathrm{OAT}-\mathrm{CO}_{2} \mathrm{H}$ 12 (blue), pure OAT- $\mathrm{CO}_{2} \mathrm{H}-12$ (red), and pure OAT- $\mathrm{CO}_{2} \mathrm{H}-6$ (black); (d) DSC thermograms of xerogels of a $1: 1$ mixture of OAT-H-6/OAT-H12 (blue), pure OAT-H-12 (red), and pure OAT-H-6 (black).

$T_{\mathrm{m}}$ values as compared to those of pure samples was probably due to the existence of eutectic component (i.e. not complete self-sorting). After annealing once to trigger the decarboxylation reaction, the resulting mixed sample of OAT-H-6 and OAT-H-8 also exhibited phase-separated self-sorting phenomenon in the melted state (Fig. 10b). Similar self-sortings were also observed for OAT-CO $\mathrm{C}_{2} \mathrm{H}-6 / \mathrm{OAT}-\mathrm{CO}_{2} \mathrm{H}-10$ (ESI Fig. S12, pS40 $\dagger$ ), and OAT-CO $\mathrm{O}_{2} \mathrm{H}-6 / \mathrm{OAT}-\mathrm{CO}_{2} \mathrm{H}-12$ (Fig. 10c). In these cases where the difference in the oligomer length becomes larger, peak separation in the mixed sample was more apparent, and the $T_{\mathrm{m}}$ values also get much closer to those of the pure components. The results indicate that when the difference in chain length becomes larger, the degree of self-sorting is also higher.

To confirm that the self-sorting actually happened during the gelation process but not due to the freeze-drying procedure, DSC experiments were also performed on the wet gels. We tested mixed wet gels $(2.5 \% \mathrm{w} / \mathrm{v}$ in $p$-xylene $)$ of OAT-CO $\mathbf{O}_{2} \mathbf{H}-6 /$ OAT-CO $\mathrm{C}_{2} \mathrm{H}-8$ and OAT-CO${ }_{2} \mathrm{H}-6 / \mathrm{OAT}-\mathrm{CO}_{2} \mathrm{H}-12$ (Fig. 11). Due to a much lower gelator concentration, the signals were relatively weak. Nonetheless, two endothermic peaks in the mixed gels could still be observed, which proved that narcissistic selfsorting happened during the formation of nano-scale assemblies in wet gels. Again, the degree of self-sorting in the mixed gel OAT-CO ${ }_{2} \mathrm{H}-6 / \mathrm{OAT}-\mathrm{CO}_{2} \mathrm{H}-12$ was higher than that in OAT$\mathrm{CO}_{2} \mathrm{H}-6 / \mathrm{OAT}-\mathrm{CO}_{2} \mathrm{H}-8$. Hence, the extent of self-sorting of the xerogels could actually reflect that of the wet gel systems.

Self-sorting between oligomers of the OAT-COPrg- $(2 n+1)$ series was also investigated (Fig. 12). In the recorded DSC thermogram of a mixture of OAT-COPrg-7/OAT-COPrg-9, two peaks showed up which proved that when the difference of the 

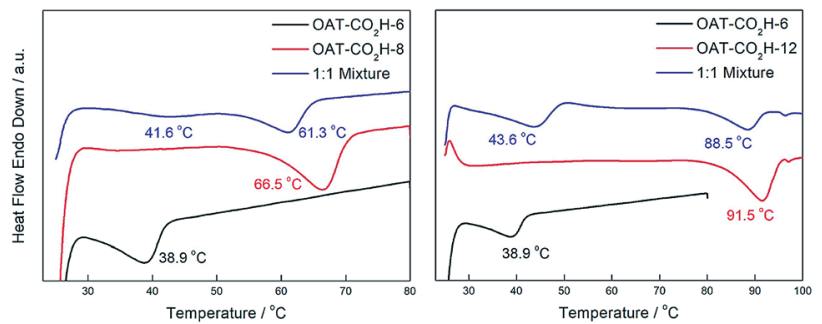

Fig. 11 Left: DSC thermograms of wet gels (2.5\% w/v in $p$-xylene) of a $1: 1$ mixture of OAT- $\mathrm{CO}_{2} \mathrm{H}-6 / \mathrm{OAT}-\mathrm{CO}_{2} \mathrm{H}-8$ (blue), pure OAT$\mathrm{CO}_{2} \mathrm{H}-8$ (red) and pure OAT- $\mathrm{CO}_{2} \mathrm{H}-6$ (black); right: DSC thermograms of wet gels $\left(2.5 \% \mathrm{w} / \mathrm{v}\right.$ in $p$-xylene) of a $1: 1$ mixture of OAT- $\mathrm{CO}_{2} \mathrm{H}-6$ / OAT- $\mathrm{CO}_{2} \mathrm{H}-12$ (blue), pure OAT- $\mathrm{CO}_{2} \mathrm{H}-12$ (red) and pure OAT- $\mathrm{CO}_{2} \mathrm{H}-$ 6 (black).

number of CONH units between two OAT molecules was larger than one, self-sorting would be exhibited in the gelation process. Slightly phase separated phenomenon could also be observed in the annealed blends even though the peaks shrunk badly after the annealing procedure, implying that kinetic trapping in the melted state prevented the majority of the oligomers from self-assembling into a structurally order structure. Similarly, self-sorting was clearly observed with the mixed xerogel of OAT-COPrg-7/OAT-COPrg-11. However, no endotherm could be found in the annealed sample, suggesting that the two oligomers were kinetically trapped and could not form any crystalline zone upon cooling. It was believed that the higher oligomer OAT-COPrg-11 was completely devoid of kinetic freedom due to the chain entanglement in the melted state as a result of its longer chain structure.

On the other hand, when OAT-CO $\mathbf{C}_{2} \mathbf{H}-6$ and OAT-COPrg-7 were mixed together, only one peak appeared and the $T_{\mathrm{m}}$ was almost in the middle of those of two pure samples (ESI
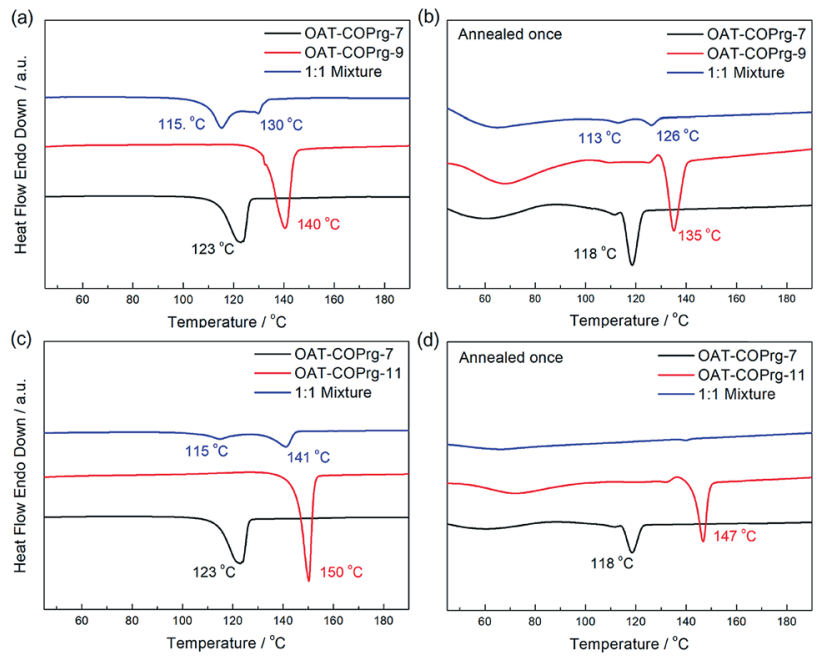

Fig. 12 DSC thermograms of xerogels (2.5\% w/v in $p$-xylene): (a) $1: 1$ mixture of OAT-COPrg-7/OAT-COPrg-9 (blue), pure OAT-COPrg-9 (red), and pure OAT-COPrg-7 (black) with (b) annealed samples; (c) $1: 1$ mixture of OAT-COPrg-7/OAT-COPrg-11 (blue), pure OATCOPrg-11 (red), and pure OAT-COPrg-7 (black) with (d) annealed samples.
Fig. S13a, pS41†). This result indicated that when the difference of the number of $\mathrm{CONH}$ was only one, no self-sorting could be observed. Similar non-sorting was also observed for OAT-H-6 and OAT-COPrg-7 (ESI Fig. S13b, pS41†).

XRD measurement was also conducted on the self-sorted $1: 1$ mixed gel of OAT-CO $\mathbf{O}_{2} \mathbf{H}-6 / \mathrm{OAT}-\mathrm{CO}_{2} \mathbf{H}-12$ (ESI Fig. S4, pS34 $\dagger$ ). The peak pattern of the mixture was very similar to that of $\mathbf{O A T}-\mathrm{CO}_{2} \mathbf{H}$ 6 or that of OAT-CO $\mathbf{O}_{2} \mathbf{H}-12$, i.e. both the side chain interdigitation and $\pi-\pi$ stacking peaks could be observed. However, it should be noted that XRD experiment could not differentiate a self-sorted or a randomly mixed system because both systems will give the same diffraction pattern. Since the oligomer chains are not bundled up in a regular fashion, hence the diffraction pattern due to a difference of oligomer chain length could not be detected. SEM analysis of the self-sorted 1:1 mixture of OAT$\mathrm{CO}_{2} \mathrm{H}-6 / \mathrm{OAT}-\mathrm{CO}_{2} \mathrm{H}-12$ also could not identify any region showing microscopic self-sorting (ESI Fig. S16, pS44†).

Semi-quantitative assessment of the degree of self-sorting. To semi-quantitatively assess the degree of self-sorting in a binary mixed gel system, the $T_{\mathrm{m}}$ values at various ratios of the two components were recorded and the corresponding phase diagrams ${ }^{29}$ were constructed. Taking the phase diagram of OAT$\mathbf{C O}_{2} \mathbf{H}-6 / \mathrm{OAT}-\mathrm{CO}_{2} \mathrm{H}-12$ xerogel as an example, the plotted eutectic phase diagram was consistent with the fact that the two oligomers exhibited limited solid solubility with each other (Fig. 13). The terminal point $E$ was assigned to be the midpoint of the two compositions where the first endothermic peak last showed up and where it first disappeared. It was noticed that the eutectic temperature was very close to the $T_{\mathrm{m}}$ of OAT-CO $\mathbf{O}_{2} \mathbf{H}-6$ such that the terminal solid solution zone was too narrow to be represented on the phase diagram. As it turned out, at 0-20 weight $\%$ of OAT- $\mathbf{C O}_{2} \mathbf{H}-12$, only one $T_{\mathrm{m}}$ value, corresponding to that of pure OAT- $\mathbf{C O}_{2} \mathbf{H}-6$ was observed. This suggested well mixing of the two oligomers. On the other hand, two $T_{\mathrm{m}}$ values, the first corresponded to that of OAT- $\mathbf{C O}_{2} \mathbf{H}-6$ and the second to OAT-CO $\mathbf{O}_{2} \mathbf{H}-12$, were found when the weight\% of OAT-CO $\mathbf{O}_{2} \mathbf{H}-12$ was around $40-60 \%$, indicating effective self-sorting in these compositions. Once the weight\% of OAT- $\mathbf{C O}_{2} \mathbf{H}-12$ reached more than $80 \%$, again only one $T_{\mathrm{m}}$ value, corresponding to that of pure OAT- $\mathbf{C O}_{2} \mathbf{H}-12$ was observed. This again indicated well mixing of the two oligomers. In theory, the green dash line (AB)

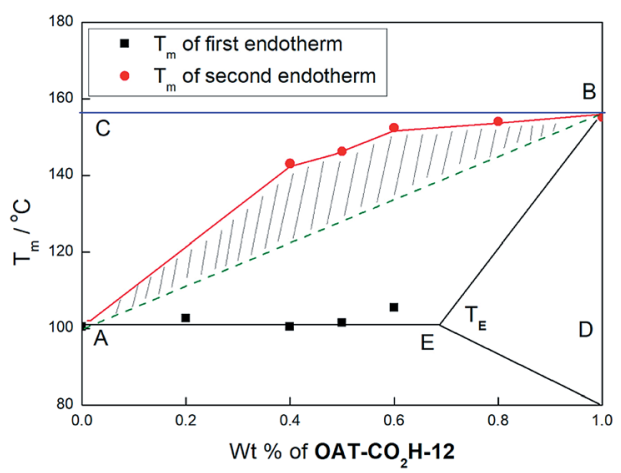

Fig. 13 Phase diagram of mixed xerogels of $\mathrm{OAT}-\mathrm{CO}_{2} \mathrm{H}-6 / \mathrm{OAT}-$ $\mathrm{CO}_{2} \mathrm{H}-12$ at different weight\% of OAT- $\mathrm{CO}_{2} \mathrm{H}-12$. 
represented the theoretical $T_{\mathrm{m}}$ at various compositions of a totally miscible mixture (i.e. no self-sorting) and the blue horizontal line (CB) represented the theoretical $T_{\mathrm{m}}$ of OAT$\mathrm{CO}_{2} \mathbf{H}-12$ in a completely immiscible mixture. Hence, the ratio $(\beta)$ of the area of the shaded polygon to the area of the triangle defined by $\mathrm{ABC}$ can be used to represent the degree of selfsorting in the binary mixture (the rationale is given in ESI pS42 $\dagger$ ). In the case of the binary system OAT-CO $\mathbf{O}_{2} \mathbf{H - 6} / \mathbf{O A T}$ $\mathrm{CO}_{2} \mathbf{H - 1 2}$, the $\beta$ value was $43 \%$. The $\beta$ values of other binary systems were similarly calculated from their corresponding phase diagrams (Table 3 and ESI Fig. S15, p43†). From the calculation results, it can be concluded that (i) when the difference of CONH number between two oligomers was larger, the self-sorting degree would be larger too, (ii) the carboxylic acid terminated oligomers exhibited slightly better self-sorting capability than the hydride terminated series, and (iii) the extent of self-sorting diminished as the lengths of the two oligomers became very large. Hence, clear self-sorting was observed in the case of OAT- $\mathbf{C O}_{2} \mathbf{H}-6 /$ OAT-CO $\mathbf{C O}_{2} \mathbf{H}-8(\beta=26 \%)$, but no self-sorting was found in the case of OAT-CO $\mathbf{O}_{2} \mathbf{H - 1 0} / \mathbf{O A T}$ $\mathbf{C O}_{2} \mathbf{H - 1 2}(\beta=0 \%)$, indicating that a levelling off effect was in operation once the number of amide units became very large. In other words, a difference of two amide units could induce good degree of self-sorting in the mixture involving two lower oligomers, but not quite enough for that of two longer ones.

Three component self-sorting system. In order to test whether the length difference would still lead to a self-sorted system containing three components, a mixed xerogel comprising of a 1:1:1 weight ratio of OAT-CO $\mathbf{O}_{2} \mathbf{H}-6$, OAT$\mathrm{CO}_{2} \mathrm{H}-8$ and OAT-CO $\mathbf{C}_{2} \mathrm{H}-12$ was subjected to DSC analysis. Three slightly overlapped endothermic peaks appeared in the DSC trace (Fig. 14). This result indicated that a certain degree of selfsorting even in a three-component mixture. As expected, the ternary system involving OAT-H-6/OAT-H-8/OAT-H-12 showed slightly inferior self-sorting ability, although three peaks could be identified, but they overlapped to a higher extent.

Self-sorting between OAT and OATe oligomers. Having investigated how a difference in the number of CONH motifs would lead to and influence the self-sorting behaviour using OATs with different lengths, we continued to explore whether a difference in the density of interaction units would also contribute to self-sorting by comparing the OAT and OATe oligomers. It has already been shown that the OATe series of compounds possessed a slightly inferior gelation strength than that of the corresponding OAT oligomers. It was therefore envisaged that this stability difference could be the driving force for self-sorting. Indeed, a mixed xerogel of $1: 1$ OAT-COPrg-7/ OATe-COPrg-7 revealed the presence of two slightly overlapping

Table 3 Calculated $\beta$ values of various oligomer blends

\begin{tabular}{|c|c|c|c|}
\hline Blend & $\beta$ & Blend & $\beta$ \\
\hline OAT- $\mathrm{CO}_{2} \mathrm{H}-6 / \mathrm{OAT}-\mathrm{CO}_{2} \mathrm{H}-8$ & $26 \%$ & OAT-H-6/OAT-H-8 & $6 \%$ \\
\hline $\mathrm{OAT}-\mathrm{CO}_{2} \mathrm{H}-6 / \mathrm{OAT}-\mathrm{CO}_{2} \mathrm{H}-12$ & $43 \%$ & OAT-H-6/OAT-H-12 & $30 \%$ \\
\hline $\mathrm{OAT}-\mathrm{CO}_{2} \mathrm{H}-8 / \mathrm{OAT}-\mathrm{CO}_{2} \mathrm{H}-12$ & $33 \%$ & OAT-H-8/OAT-H-12 & $8 \%$ \\
\hline OAT- $\mathrm{CO}_{2} \mathrm{H}-10 / \mathrm{OAT}-\mathrm{CO}_{2} \mathrm{H}-12$ & $0 \%$ & OAT-H-10/OAT-H-12 & $0 \%$ \\
\hline
\end{tabular}
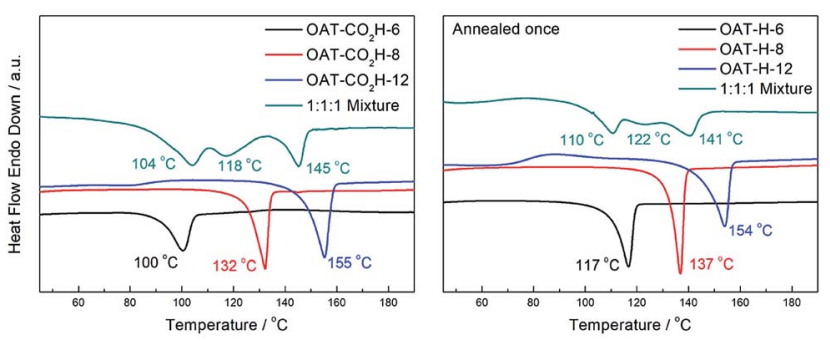

Fig. 14 Left: DSC thermograms of xerogels ( $2.5 \% \mathrm{w} / \mathrm{v}$ in $p$-xylene) prepared from a $1: 1: 1$ mixture of OAT- $\mathrm{CO}_{2} \mathrm{H}-6 / \mathrm{OAT}-\mathrm{CO}_{2} \mathrm{H}-8 / \mathrm{OAT}-$ $\mathrm{CO}_{2} \mathrm{H}-12$ (green), pure OAT- $\mathrm{CO}_{2} \mathrm{H}-12$ (blue), pure OAT- $\mathrm{CO}_{2} \mathrm{H}-8$ (red), and pure OAT- $\mathrm{CO}_{2} \mathrm{H}-6$ (black); right: DSC thermograms of a $1: 1: 1$ mixture of OAT-H-6/OAT-H-8/OAT-H-12 (green), pure OAT-H-12 (blue), pure OAT-H-8 (red), and pure OAT-H-6 (black).
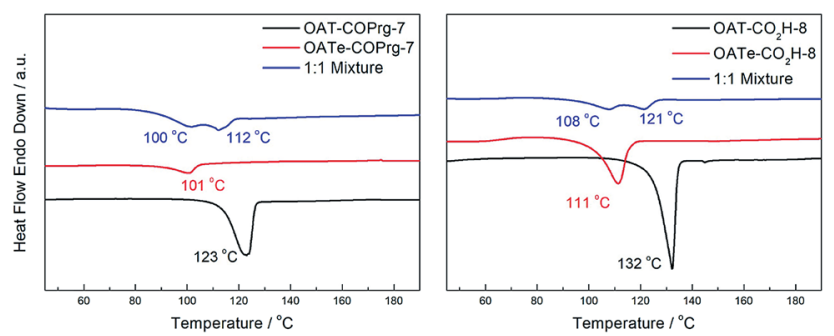

Fig. 15 Left: DSC thermograms of xerogels ( $2.5 \% \mathrm{w} / \mathrm{v}$ in $p$-xylene) prepared from a $1: 1$ mixture of OAT-COPrg-7/OAT-COPrg-7 (blue), pure OAT-COPrg-7 (red), and pure OATe-COPrg-7 (black); right: DSC thermograms of xerogels $(2.5 \% \mathrm{~W} / \mathrm{v}$ in $p$-xylene) prepared from a $1: 1$ mixture of OAT- $\mathrm{CO}_{2} \mathrm{H}-8 / \mathrm{OATe}-\mathrm{CO}_{2} \mathrm{H}-8$ (blue), pure OATe- $\mathrm{CO}_{2} \mathrm{H}-8$ (red), and pure OAT- $\mathrm{CO}_{2} \mathrm{H}-8$ (black).

endothermic peaks (Fig. 15), indicating partial self-sorting of the system. Similarly, partial self-sorting between $\mathbf{O A T}-\mathrm{CO}_{2} \mathbf{H}-8$ and $\mathbf{O A T e}-\mathrm{CO}_{2} \mathbf{H}-8$ was also noted in the mixed xerogel sample. Based on these results, it can be concluded that a difference in the density of interacting amide motifs could also lead to phaseseparated assemblies during the gelation process.

\section{Conclusions}

Several homologous series of oligo(amide-triazole)s bearing various end groups, different number and density of CONH units were successfully prepared and characterized. They were able to form strong physical gels in various aromatic solvents. According to FTIR, SAXRD and SEM experiments, the gelation network was formed by hydrogen bonding, $\pi-\pi$ stacking interactions and side chain interdigitation.

Both the number and density of CONH units were found to influence the gelation strength of the oligomers. In general, a larger number and higher density of $\mathrm{CONH}$ units could promote the formation of a stronger gelation network, but a levelling off effect was observed once the number became very large. Rather surprisingly, the end group was found to have a strong effect on the self-assembly in the melted state. Oligomers bearing a $N$-propargyl amide end group were found to be kinetically trapped and showed inferior kinetic mobility to self- 
assembly into order crystalline zones, while this was not seen in the saturated $N$-propyl amide terminated analogue.

The various oligomers were also found to exhibit different extent of self-sorting in both the wet gel and xerogel states depending on the nature of the end group, the difference in the number and density of the amide units of the constituted components. A difference of $\mathrm{CONH}$ number of two or higher was enough to show self-sorting behaviour both in two-component and three-component mixed systems. The plot of binary phase diagrams revealed that a larger difference in the CONH number would lead to a higher degree of self-sorting behaviour. At the same time, a difference in the density of interacting amide units could also lead to partial self-sorting behaviour.

To conclude, we demonstrated here that for structurally flexible, non-preorganized molecules, a slight change of the molecular structure would seriously affect their self-assembly structure and self-sorting phenomenon. Contrary to our initial presumption, narcissistic self-sorting does not just only prevail in mixtures making up of structurally very different molecules, but actually appears to be fairly general even in mixtures of structurally closely related homologs.

\section{Conflicts of interest}

There are no conflicts to declare.

\section{Acknowledgements}

We thank the Research Grants Council, HKSAR (Ref No. 14301114) and the Faculty of Science, CUHK (Account no. 3132670) for the financial support.

\section{Notes and references}

1 M. M. Safont-Sempere, G. Fernández and F. Würthner, Chem. Rev., 2011, 111, 5784-5814.

2 K. Osowska and O. Š. Miljanić, Synlett, 2011, 1643-1648.

3 M. L. Saha and M. Schmittel, Org. Biomol. Chem., 2012, 10, 4651-4684.

4 Z. He, W. Jiang and C. A. Schalley, Chem. Soc. Rev., 2015, 44, 779-789.

5 K. A. Jolliffe, P. Timmerman and D. N. Reinhoudt, Angew. Chem., Int. Ed., 1999, 38, 933-937.

6 Y. Ma, S. V. Kolotuchin and S. C. Zimmerman, J. Am. Chem. Soc., 2002, 124, 13757-13769.

7 A. Wu and L. Isaacs, J. Am. Chem. Soc., 2003, 125, 4831-4835.

8 R. Krämer, J.-M. Lehn and A. Marquis-Rigault, Proc. Natl. Acad. Sci. U. S. A., 1993, 90, 5394-5398.

9 M. Yoshizawa, M. Nagao, K. Kumazawa and M. Fujita, J. Organomet. Chem., 2005, 690, 5383-5388.

10 R. J. Sarma and J. R. Nitschke, Angew. Chem., Int. Ed., 2008, 47, 377-380.

11 T. R. Cook and P. J. Stang, Chem. Rev., 2015, 115, 7001-7045.

12 L. R. Holloway, P. M. Bogie and R. J. Hooley, Dalton Trans., 2017, 46, 14719-14723.

13 M. Schmittel and S. Saha, From Self-Sorting of Dynamic Metal-Ligand Motifs to (Supra)Molecular Machinery in
Action, in Advances in Inorganic Chemistry, ed. R. van Eldik and R. Puchta, Elsevier Inc., London, UK, 2018, vol. 71, Supramolecular Chemistry, pp. 135-175.

14 B. Bilgiçer, X. Xing and K. Kumar, J. Am. Chem. Soc., 2001, 123, 11815-11816.

15 L. Isaacs, Acc. Chem. Res., 2014, 47, 2052-2062.

16 X.-Q. Wang, W. Wang, Y.-X. Wang and H.-B. Yang, Chem. Lett., 2015, 44, 1040-1046.

17 Q. Ji, R. C. Lirag and O. Š. Miljanić, Chem. Soc. Rev., 2014, 43, 1873-1884.

18 A. Herrmann, Chem. Soc. Rev., 2014, 43, 1899-1933.

19 A. Wilson, G. Gasparini and S. Matile, Chem. Soc. Rev., 2014, 43, 1948-1962.

20 F. Beuerle, S. Klotzbach and A. Dhara, Synlett, 2016, 27, 1133-1138.

21 G. ten Brinke, Polym. Sci. A Compr. Ref., 2012, vol. 1, pp. 287313.

22 For an example of social self-sorting of preorganized oligomers, see M. Li, K. Yamato, J. S. Ferguson and B. Gong, J. Am. Chem. Soc., 2006, 128, 12628-12629.

23 A. P. Bisson, F. J. Carver, D. S. Eggleston, R. C. Haltiwanger, C. A. Hunter, D. L. Livingstone, J. F. McCabe, C. Rotger and A. E. Rowan, J. Am. Chem. Soc., 2000, 122, 8856-8868.

24 For a review of self-sorting in polymers, see C. R. South, C. Burd and M. Weck, Acc. Chem. Res., 2007, 40, 63-74.

25 E. Wisse, L. E. Govaert, H. E. H. Meijer and E. W. Meijer, Macromolecules, 2006, 39, 7425-7432.

26 J. Kumaki, T. Kawauchi, K. Ute, T. Kitayama and E. Yashima, J. Am. Chem. Soc., 2008, 130, 6373-6380.

27 J. Zhang, H.-F. Chow, M.-C. Chan, G. K. W. Chow and D. Kuck, Chem.-Eur. J., 2013, 19, 15019-15025.

28 C.-F. Leung and H.-F. Chow, Chem.-Eur. J., 2017, 23, 48274836.

29 A. S. W. Chan and P. R. Sundararajan, J. Phys. Chem. B, 2016, 120, 9253-9263.

30 For a review on the self-sorting of low molecular weight multi-component gels, see L. E. Buerkle and S. J. Rowan, Chem. Soc. Rev., 2012, 41, 6089-6102.

31 A. E. Stross, G. Iadevaia and C. A. Hunter, Chem. Sci., 2016, 7, 94-101.

32 G. Iadevaia, A. E. Stross, A. Neumann and C. A. Hunter, Chem. Sci., 2016, 7, 1760-1767.

33 A. E. Stross, G. Iadevaia and C. A. Hunter, Chem. Sci., 2016, 7, 5686-5691.

34 D. Núñez-Villanueva and C. A. Hunter, Chem. Sci., 2017, 8, 206-213.

35 See ESI for details. $\dagger$

36 V. V. Rostovtsev, L. G. Green, V. V. Fokin and K. B. Sharpless, Angew. Chem., Int. Ed., 2002, 41, 2596-2599.

37 A. P. Bisson, F. J. Carver, D. S. Eggleston, R. C. Haltiwanger, C. A. Hunter, D. L. Livingstoe, J. F. McCabe, C. Rotger and A. E. Rowan, J. Am. Chem. Soc., 2000, 122, 8856-8868.

38 K.-N. Lau, H.-F. Chow, M.-C. Chan and K.-W. Wong, Angew. Chem., Int. Ed., 2008, 47, 6912-6916.

39 M. Roman, C. Cannizzo, T. Pinault, B. Isare, B. Andrioletti, P. van der Schoot and L. Bouteiller, J. Am. Chem. Soc., 2010, 132, 16818-16824. 